\title{
The application practice of filling mining technique in Yuyang coal mine
}

\author{
Pengliang Liu \\ ( Beijing Mining Technology Department, Tiandi Science and Technology Co. , Ltd. , Beijing \\ 100013 , China )
}

Key words:filling mining;wind-blown sand paste-like;high-water flexible formwork powered support for stowing;seal

\begin{abstract}
In order to liberate "three unders" mining and improve the relationship between enterprises and government, maintaining the harmonious and stable order of mining area,on the basis of full investigation demonstrated, Yuyang coal mine had bring in a practical way of filling mining. In the practice of filling mining, Yuyang coal mine creatively improved the material and craft of filling, highlighted the scale,characteristics of localization, mechanization and automation. Project practice show that the technology had considerable economic benefit, prominent craft features and ecological good environment benefit.
\end{abstract}

\section{Introduction}

Traditional mining method is easy to cause a large area of goaf collapse, affect the ecological environment balance, damage the ground buildings,and restricte further development of mining area.Strip mining method which reduce surface subsidence will cause a great waste of coal resources,and the pillar cann't guarantee the long-term stability of surface.Therefore, it the is necessary to apply filling mining.

\section{The background of filling mining in Yuyang coal mine}

Shaanxi Zhongneng Coalfield Co.,Ltd.is mainly engaged in coal mining,coal processing,marketing, production and operation activities. Yuyang coal mine is the subordinate productive mine of the company, and it is in northeast of shaanxi Jurassic coal field yulin-hengshan mining area(north). The administration of Yuyang coal mine belongs to Yuyang district of Yulin city territory,and it is about $12 \mathrm{~km}$ away from yulin. There are many ground objects in mine,over $40 \% \sim 50 \%$ of the total reserves of coal resource was constructed. The area of arranging longwall working face in mining field area was limited, and the resource loss was great.Because of rapidly economic growth in recent years,yulin city planning scope expanded rapidly, city planning put forward higher requirements to Yuyang coal mine mining subsidence.So,Yuyang coal mine use filling mining to reduce the impact on the ground and damage.

\section{Filling technique scheme selection}

The buried depth of No. 3 coal seam of Yuyang coal mine is $141.01 \sim 201.19 \mathrm{~m}$, the thickness of the coal seam is between $2.90 \sim 3.99 \mathrm{~m}$, and the average thickness is $3.6 \mathrm{~m}$. The lithology of the coal bed 
roof is dominated by medium grained sandstone, fine sandstone, and the bottom is dominated by mudstone and silty mudstone.Filling mining is a kind of green mining technology, which can effectively control the surface subsidence in recent years.It is the goaf management and control technology that as coal mining working face advancing, filling mined-out area into waste rock, sand, industrial solid waste, and other materials as filling body. From the filling materials, At present, the main application of coal gangue, fly ash, etc.; From the packing material form, mainly for the solid filling,the paste(like) filling and (ultra) high water filling three categories.

According to the current development trend of filling mining technology and the characteristics of Yulin local materials, the main filling material is chosen as the main filling material.Combining with Yuyang coal mine geological and mining conditions.A comprehensive analysis and comparison of four kinds of filling methods, such as the direct filling of the wind blown sand, the paste filling of the wind blown sand as aggregate, the high water swelling material filling of the wind blown sand, and ultra high water material filling. Aeolian sand paste like backfill has the advantages of simple process, appropriate, controllable flow, plugging simple, local materials, low cost, etc. excellent characteristics of expansion. The final choice is the wind blown sand paste-like material gravity flow filling technology - based filling method.

\section{Filling mining technology design}

The basic principles of design:

(1) innovate packing material, the basic realization of local materials;

(2) filling system mechanization and automation level;

(3) filling mining production capacity reaches a certain size, is the domestic industry;

(4)economic, ecological and environmental benefits, give attention to two or morethings demonstration promotion value.

\section{Filling process system}

The mining filling design of Yuyang coal mine is divided into two kinds method, which is connected to the narrow strip and the fully mechanized long wall. Each process includes two main systems of mining and filling. The conventional process of the two kinds of mining technology is the narrow strip and the long wall, The filling system includes the pulping system, slurry transportation system, monitoring and controlling system, and the slurry seal equipment.The filling process system is shown in Fig.1. 


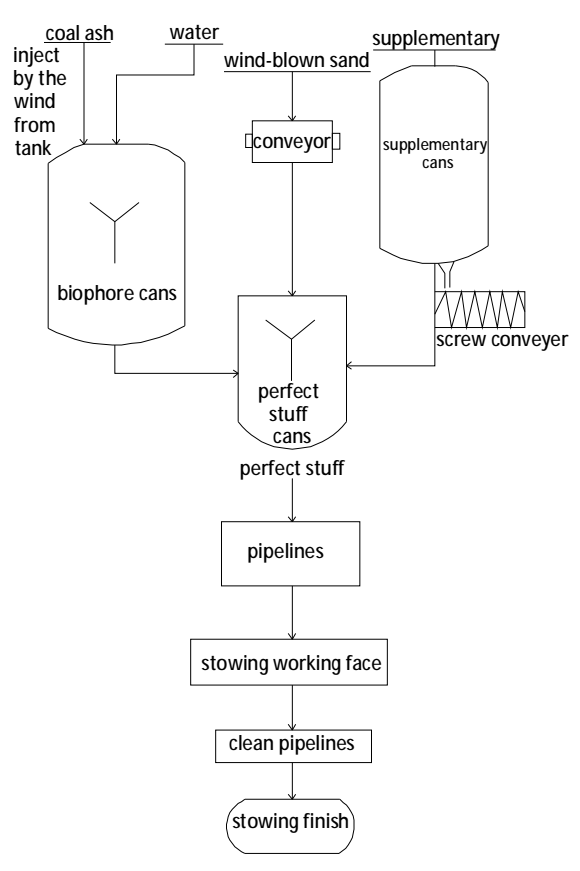

Fig.1 Filling mining technology system schematic diagram

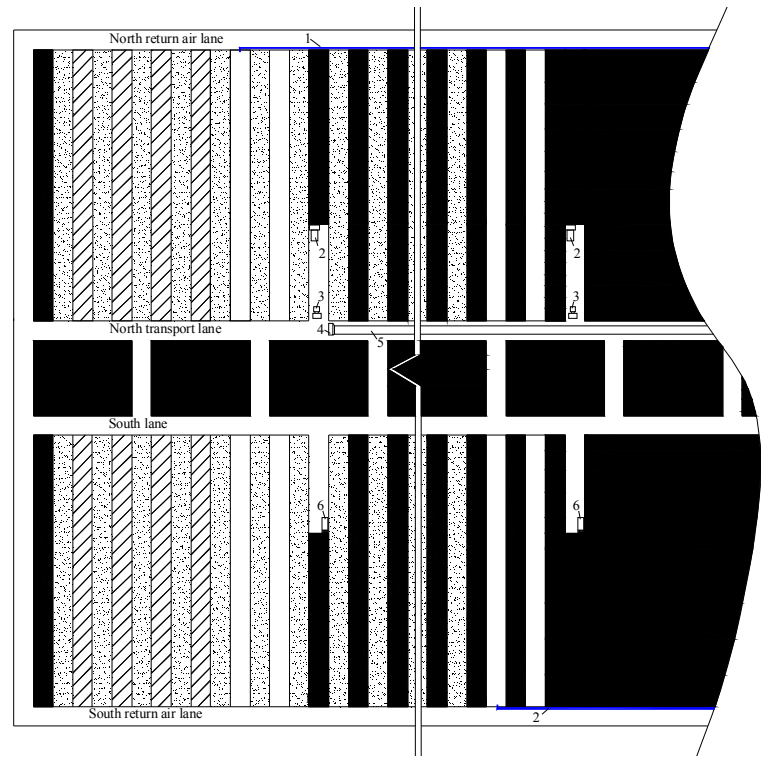

1-filling line; 2-the continuous miner; 3-shuttle car; 4-crusher;5-belt conveyor; 6-anchor machine

Fig.2 Mining filling of two phrases operation at the same time

Filling system of Yuyang coal mine was composed of two set of ability of the same system, each system can be run separately or at the same time, the design capacity was $2 \times 180 \mathrm{~m}^{3} / \mathrm{h}$. Each system was composed of pulping system and pipeline system. Pulping system was composed of storage facilities of fly ash, aeolian sand, accessories, quantitative preparation material, slurry preparation, water slurry preparation and automatic control device. Filling pipeline system was composed of transporting vertical drilling pipes, underground tunnel horizontal pipeline, slurry valve, flow meter, pressure sensor, the 3-way valve etc. On the basis of the introduction of patent technology, we development aeolian sand adding system, storage of fly ash conveying system and automation control monitoring system.

\section{continuous miner filling mining:}

Design production capacity of continuous miner filling mining working face is $400000 \mathrm{t} / \mathrm{a}$, the coal mining method is same to conventional continuous miner mining. Mining and filling was divided in two stages, the first phase of mining and filling interval is 2 5 lane,conduct second phase of mining and fillingwait after the first phase of filling body strength to meet the design strength.According to the mining machine performance and the nature of the roof, and mining efficiency,we choose reasonable mining width and coal pillar size.The mining and filling sequence as shown in Fig.2.

\section{Fully mechanized filling mining:}

Filling capacity design of fully mechanized working face is 1 million t/a, the face arrangement is the same to common longwall fully mechanized working face.Filling process is concentration filling after mining $4 \sim 8$ knife.Introduced the soft sealing technology for fully mechanized filling material slurry seal.Fully mechanized mining face filling sealing methods as shown in Fig.3. 


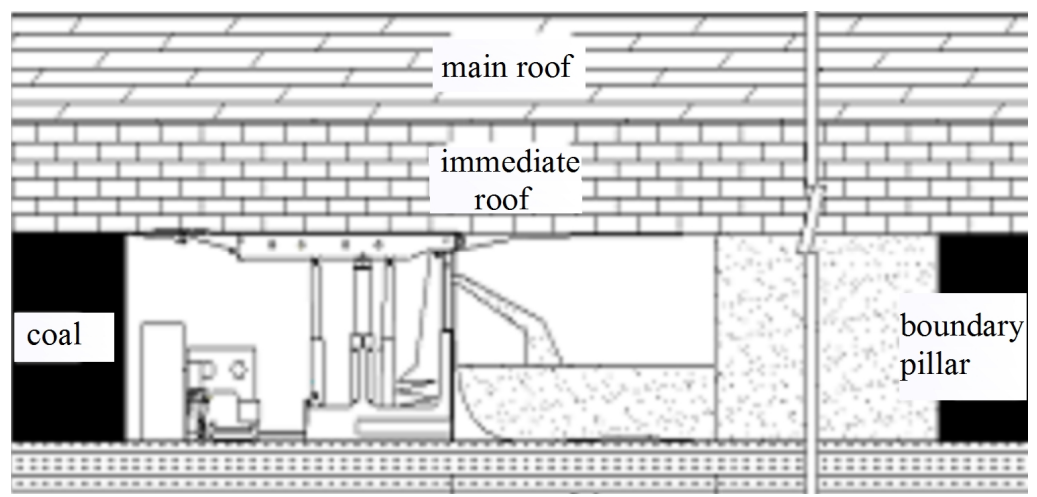

Fig.3Fully mechanized working face filling block diagram

\section{Filling mining practice}

(1) After ground pulp filling station was put into operation, Yuyang coal mine increase the storage and transportation of fly ash system; Increase the dust removal equipment, improve the dust removal system, improve the effect of dust;optimize wind-blown sand filter system. The system stability, handling, risk resistance ability reached a higher level, a single set of pulping and pipeline system practical ability can reach more than $200 \mathrm{~m}^{3} / \mathrm{h}$,Provides the filling safeguard for the filling mining scale production capacity of one million tons.

(2) continuous miner filling mining face at present a total of 50 filling mining filling surface lane,filling slurry is about $52000 \mathrm{~m}^{3}$, All the indexes for example filling body strength and stability etc.meet the design requirements; So far, date, the cumulative advance of fully mechanized face filling is more than $200 \mathrm{~m}$, the coal is about $130000 \mathrm{t}$, filling slurry is about $100000 \mathrm{~m}^{3}$.

(3) Set up the surface movement observation station and underground mine pressure monitoring system, has formed a relatively perfect feedback system for the filling mining strata movement control effect and ground protection. Collecting data and accumulating technical data for summarizating research results of filling mining and application.

\section{Achievements:}

(1) Basically mastered the law of pipe packing material, understand the indicators of the filling material and the performance, increase the wind-blown sand weight in filling material, optimized the ratio of filling material, implements the local materials, slather aeolian sand as the aggregate of filling material, substantially reducing the costs of filling material.

(2) Research and development continuous miner filling mining efficient support retaining wall, formulate the technical measures of filling pick up rate, formed the characteristics of Yuyang coal mine fully mechanized after filling sealing technology, tight-filling ratio of fully mechanized filling meet the requirements of the process and roof control. Craft of continuous miner filling mining and filling with fully mechanized mining has gradually matured, established filling quality standardization standards and assessment score method of continuous miner filling mining and fully mechanized mining.

(3) mastered temperature change rule of the underground filling body and its influence on coal seam,monitoring the heat and gas release composition of filling body,mastering the influence of filling on the underground environment, all the indexes in the related disciplines security permission scope.

(4)Retaining a lane for next sublevel technology was applied in fully mechanized filling mining face, reserved next working face gateway roadway at the same time of filling, increase the observe 
space and depth of filling body and the mine pressure observation, speeds up the test process;non-pillar mining is realized,and decrease the roadway tunneling amount, improve the coal recovery rate.

(5)Comprehensivly testing the wind-blown sand, fly ash, gypsum, lime, additives and filling gel secrete water in yu Yang coal filling, show that all does not contain the composition of polluting water and soil, no pollute the groundwater and soil.

\section{Core technology}

(1) after a series of laboratory test and industrial test, independent research and develope the filling auxiliary material and additive using of yulin local raw material, have the production condition of filling auxiliary material and local of additive, at present is applying for relevant patent.

(2)Research and develope continuous miner filling mining efficient support wall and the fully mechanized mining filling face filling sealing technology with Yuyang coal mine characteristic, solved the difficult problem of slurry liquid and not closed, is applying patents for filling material sealing process.

(3) After a thorough research and a large number of experiments, fish out wind-blown sand material mixture ratio,embodying regional characteristics of using local cheap widespread aeolian sand as filling material, improve the economic benefits of filling mining from the aspects of cost control.

\section{Filling effect analysis}

By filling mining, Yuyang coal mine can extraly liberate coal resources ("three unders" mining) 17.935 million $t$, recycle resources 12.8 million $t$, According 280 yuan/t to the calculation, increase the output value of 3.584 billion yuan. Filling mining can reduce or prevent overlying strata damage and mining surface subsidence, can greatly reduce the impact on the ecological environment, maintain effectively continued improvement of the local ecological environment.Filling mining is not only conducive to the harmonious development of the company and the local economy, but also is an important technical approach to solve the coal mine goaf management, prevention and control of coal mine water, fire-fighting and other disasters, have significant popularize and demonstration meaning.

\section{References:}

[1] Feng Cui,Hua-xing Zhang,Peng-liang Liu,et al.Study on Water Conservation Mining with Aeolian Sand Paste Backfill in Coal Mine at Desert Border[J].Coal Science and Technology, 2011,39(2):10 13,27.

[2] Hu Bingnan.Backfill mining technology and development tendency in China coal mine[J] .

Coal Science and Technology,2012,40(11):1 5 .

[3]Zhu Jun.Development of High-water Flexible Formwork Powered Support for Stowing[J].Coal mining Technology,2013,18(2) :32-33,10 . 